\title{
Boot Camp Translation: A Method For Building a Community of Solution
}

\author{
Ned Norman, Chris Bennett, Shirley Cowart, Maret Felzien, Martha Flores, \\ Rafael Flores, Connie Haynes, Mike Hernandez, Mary Petra Rodriquez, \\ Norah Sanchez, Sergio Sanchez, Kathy Winkelman, Steve Winkelman, \\ Linda Zittleman, MSPH, and John M. Westfall, MD, MPH
}

Objective: A crucial yet currently insufficient step in biomedical research is the translation of scientific, evidence-based guidelines and recommendations into constructs and language accessible to every-day patients. By building a community of solution that integrates primary care with public health and community-based organizations, evidence-based medical care can be translated into language and constructs accessible to community members and readily implemented to improve health.

Methods: Using a community-based participatory research approach, the High Plains Research Network (HPRN) and its Community Advisory Council developed a process to translate evidence into messages and dissemination methods to improve health in rural Colorado. This process, called Boot Camp Translation, has brought together various community members, organizations, and primary care practices to build a community of solution to address local health problems.

Results: The HPRN has conducted 4 Boot Camp Translations on topics including colon cancer prevention, asthma diagnosis and management, hypertension, and the patient-centered medical home. Thus far, the HPRN has used Boot Camp Translations to engage more than 1000 rural community members and providers. Dissemination of boot camp messaging through the community of solution has led to increased colon cancer screening, improved care for asthma, and increased rates of controlled blood pressure.

Conclusions: Boot Camp Translation successfully engages community members in a process to translate evidence-based medical care into locally relevant and culturally appropriate language and constructs. Boot Camp Translation is an appropriate method for engaging community members in patient-centered outcomes research and may be an appropriate first step in building a local or regional community of solution.(J Am Board Fam Med 2013;26:254-263.)

Keywords: Asthma, Cancer Screening, Colorectal Cancer, Community-Based Participatory Research, Practice-based Research, Rural Health

The magnitude and nature of the work required to translate findings from medical research into valid

This article was externally peer reviewed.

Submitted 12 September 2012; revised 14 January 2013; accepted 4 February 2013.

From the Community Advisory Council of the High Plains Research Network (NN, CB, SC, M. Felzien, M. Flores, RF, CH, MH, MPR, NS, SS, KW, SW); and the ${ }^{2}$ High Plains Research Network, Department of Family Medicine, University of Colorado Denver School of Medicine, Aurora (LZ, JMW).

Funding: This project was supported by Cooperative Agreement No. 5 U48 DP000054-02 from the Centers for Disease Control and Prevention; by an implementation grant from the Caring for Colorado Foundation for Community AIR; and by National Institutes of Health (NIH)/ National Center for Advancing Translational Sciences Col- and effective clinical practice have been grossly underestimated. It frequently takes years or even decades for scientific discoveries to reach everyday clinical practice. ${ }^{1}$ Many discoveries never make it

orado Clinical and Translational Science Award Grant No. UL1 TR000154. The contents are solely the responsibility of the authors and do not necessarily represent the official views of the Centers for Disease Control and Prevention or the NIH.

Conflict of interest: none.

Corresponding author: John M. Westfall, MD, MPH, High Plains Research Network, Department of Family Medicine, University of Colorado Denver School of Medicine, PO Box 6508, Aurora, CO 80045-0508 (E-mail: Jack.Westfall@ ucdenver.edu). 
into daily practice. ${ }^{2,3}$ Numerous barriers limit the movement of evidence-based treatments into clinical practice. ${ }^{4-6}$ Poor adoption of evidence-based recommendations may be the result of the very research enterprise that created the recommendation. Scientific discoveries often use research terms, advanced clinical language, and medical constructs that are not understood by patients and community members. ${ }^{7}$ Translation of scientific, evidencebased guidelines and recommendations into constructs and language accessible to patients and community members may improve outcomes. If community members do not fully understand a preventive health care recommendation, they will not seek care to receive it. If patients do not fully understand the conceptual framework for a health condition and treatment options, they will not be able to engage in a meaningful conversation with a health care provider, successfully choose appropriate treatment options based on their preferences, or maintain adherence to recommended therapy.

Community engagement may be essential to achieving the mission of translating the best evidence into community and clinical practice to improve the health and well-being of the population. Community engagement efforts enhance public trust through long-term relationships with community-based groups. ${ }^{8}$ We believe the most appropriate framework for building and sustaining community engagement in the translational research process is community-based participatory research (CBPR), which is defined as a collaborative process that equitably involves all partners in the research process and recognizes the unique strengths that each brings. CBPR begins with a research topic of importance to the community, with the aim of combining knowledge and action for social change to improve community health and eliminate health disparities. ${ }^{9}$ More than a decade of experience with CBPR has shown that research can be more relevant, culturally proficient, and effective when conducted through community-academic partnerships. ${ }^{10-13}$ Rural communities often have a strong sense of civic duty and may be poised to develop robust communities of solution to provide local answers to local health problems. ${ }^{14}$ Engaging a broad spectrum of community members and health care providers in a locally prioritized health problem can provide the beginning steps for developing a community of solution that fosters stronger, more productive relationships between the community, patients, and their health care providers.

\section{Objectives}

The purpose of this article is to describe Boot Camp Translation (BCT), developed and used in the High Plains Research Network (HPRN) to translate the medical information of evidencebased guidelines and recommendations into common language and constructs accessible to community members and patients.

\section{Methods}

Housed in the Department of Family Medicine at the University of Colorado, Denver, Anschutz Medical Campus, the HPRN is a geographically based practice-based research network covering nearly 30,000 square miles in 16 counties in eastern Colorado (Figure 1). The HPRN consists of collaboration between 16 community hospitals, 55 practices, 120 primary care clinicians, 20 nursing homes, several public health departments, and about 145,000 residents. ${ }^{15-19}$ The HPRN includes an active community advisory council (CAC) of local farmers, ranchers, school teachers, and others to help guide and ground its research in real patient experience. The creation of the CAC in 2003 required numerous phone calls and face-to-face meetings between the HPRN director and potential community members. Community members were identified by local physicians, public health professionals, hospital administrators and through discussions with other community members in the region.

The HPRN has been translating evidence-based recommendations into evidence-based information with high integrity using community members, patients, and the broader health care community for 8 years. ${ }^{20-24}$ This work has resulted in development of health care constructs and language that are readily accessible and understandable to a broad range of rural community members and patients, have prompted increased conversations between patients and health care providers, and have improved the care provided and received for a host of health care issues including colon cancer prevention, asthma management, and hypertension. BCT identifies patient health care priorities, brings together key stakeholders to address issues related to these health care priorities, and develops and re- 
Figure 1. High Plains Research Network.

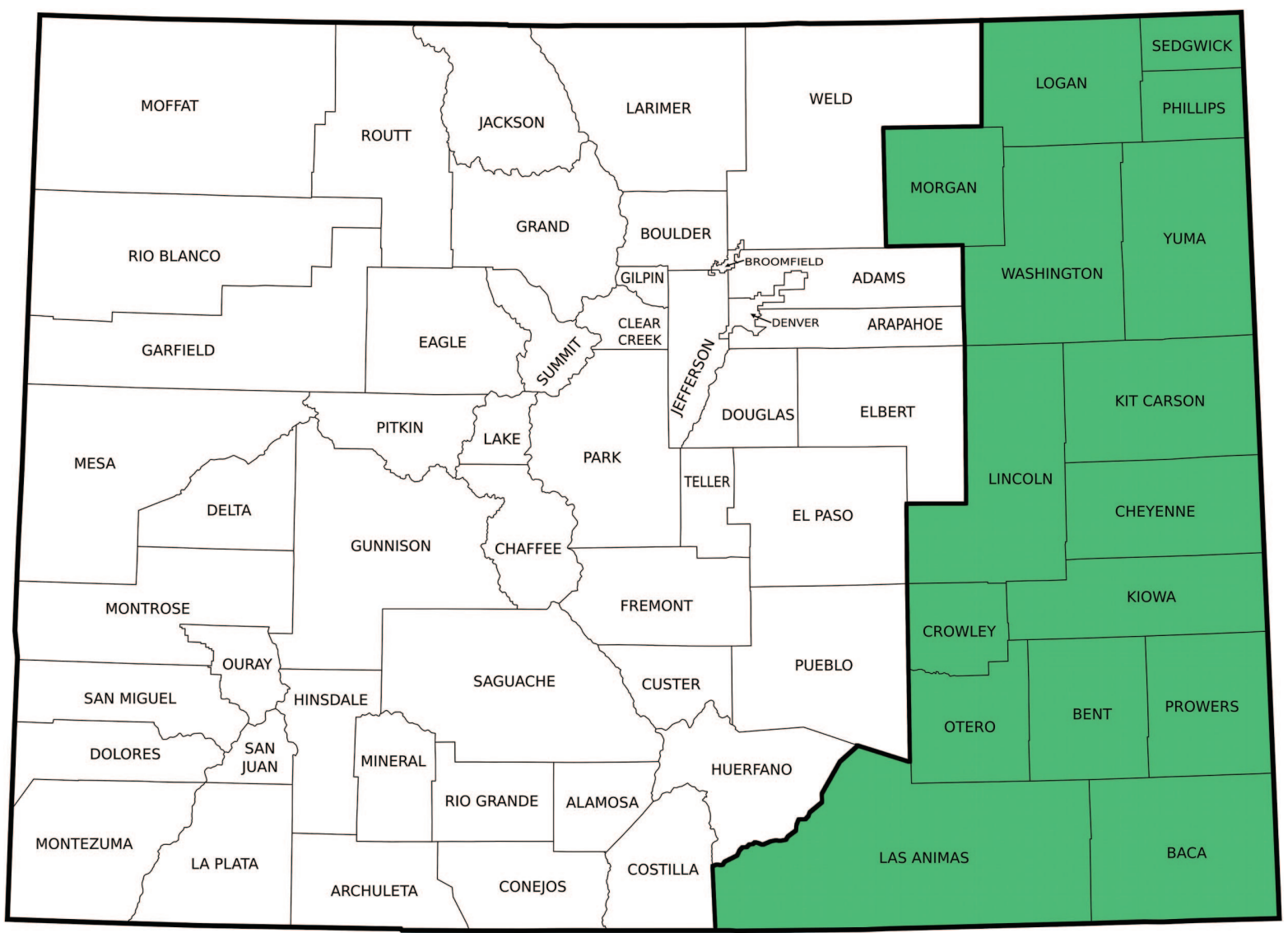

fines evidence-based care in a manner that acknowledges and respects local culture and individual patient preferences.

BCT employs a community-based participatory research approach to develop and test the messages about and dissemination strategies for a variety of health care issues in rural and frontier communities. Topics are chosen based on community priorities, CAC member interest, funding opportunities, or all three. Local community members know the "problem shed" for their priority health concerns, so they may be in the best position to identify solutions. For instance, community members identified asthma and behavioral health as priority health issues. Colon cancer was not on the priority list; however, after learning about the prevalence of colon cancer in eastern Colorado and learning about funding possibilities from the Centers for Disease Control and Prevention, the CAC chose this as an opportunity to receive substantial funding to address an important health issue in their community. The CAC considers potential projects pre- sented by researchers from the University of Colorado and chooses topics based on the community priority list, the potential for funding, and the opportunity to have an impact in their community. For each project, the core CAC is joined by various other key stakeholders in the community: 1 to 3 local physicians or other health professionals, representatives of the health department, hospital administrators, patients with the condition of interest, students, and community organization leaders. The CAC has led the development of all aspects of the projects and assisted with analysis, interpretation of results, and dissemination of the findings. ${ }^{20,21,23,25}$

\section{Boot Camp Translation}

The overall goal of BCT is to take evidence-based guidelines and recommendations; change them from formal medical information and language into a format that is accessible, understandable, meaningful, and engaging to community members; and then use that construct as the basis for a commu- 
Table 1. Boot Camp Translation Participants

\begin{tabular}{|c|c|}
\hline Participant & Occupation \\
\hline \multicolumn{2}{|l|}{ Community Advisory Council members } \\
\hline Christopher Bennett & High school and college student \\
\hline Shirley Cowart & Retired school administrative assistant \\
\hline Maret Felzien & College instructor and fourth-generation rancher \\
\hline Martha Flores & Realtor, college instructor, and medical translator \\
\hline Rafael Flores & Realtor \\
\hline Connie Haynes & Retired teacher and wheat farmer \\
\hline Garry Haynes & Retired wheat farmer \\
\hline Mike Hernandez & Retired teacher in state prison system \\
\hline Hilary Lengel & High school student \\
\hline Ned Norman & Rancher and photographer \\
\hline Mary Rodriquez & Home health paraprofessional \\
\hline Norah Sanchez & Assistant at dentist office \\
\hline Sergio Sanchez & Manager of a hardware store \\
\hline Carly Schrade & High school student \\
\hline Karyssa Schuppe & High school student \\
\hline Kathy Winkelman & Elementary school teacher \\
\hline Steve Winkelman & Third-generation wheat and tree farmer \\
\hline \multicolumn{2}{|l|}{ Ad hoc members (boot camp topic) } \\
\hline Saeid Ahmadpour (colon cancer) & Local family physician \\
\hline Ann Barton (asthma) & Public health department worker and nurse \\
\hline Pat Bates (asthma) & Public health department worker and nurse \\
\hline Arlene Harms (colon cancer) & Hospital administrator \\
\hline Denise Hase (colon cancer) & Public health department worker \\
\hline Becky Herron (asthma) & Nurse and local Board of Cooperative Educational Services worker \\
\hline Gary Koch (asthma) & Farmer and local Board of Cooperative Educational Services worker \\
\hline Erin Mellott (asthma and hypertension) & Local physician assistant \\
\hline James Miller (colon cancer) & Local primary care physician \\
\hline Kindra Mulch (colon cancer) & County director of Health and Human Services \\
\hline Richard Reutzel (asthma) & Local community member with interest in topic \\
\hline \multicolumn{2}{|l|}{ HPRN team } \\
\hline Susan Gale & Liaison/research assistant, southeast HPRN \\
\hline Christin Sutter & Quality improvement practice coach, northeast HPRN \\
\hline Marc Ringel & Retired family physician, writer \\
\hline Jack Westfall & Family physician, HPRN director \\
\hline Linda Zittleman & HPRN associate director \\
\hline \multicolumn{2}{|l|}{ Topic experts } \\
\hline Lauren DeAlleaume & Family physician, presented on hypertension \\
\hline Perry Dickinson & Family physician, presented on patient centered medical home \\
\hline Doug Fernald & Evaluator and practice-based researcher, presented on health risk assessments \\
\hline Fred Grover, Jr. & Physician, presented on colon cancer \\
\hline Lori Jarrell & Nurse and Asthma Toolkit trainer, presented on asthma \\
\hline
\end{tabular}

HPRN, High Plains Research Network.

nity-wide campaign. BCT aims to create patients and community members who can better understand the relevance of a condition or guideline, are better prepared to discuss the issue, and are more motivated to take action. Ultimately, BCT has the potential to change the local conversation about the health issue. The team of community members, providers, and research team members (Table 1) typically address 2 basic questions: What do we need to say in our message to the community? How do we disseminate that message to our community? This process develops the messages that integrate 
Table 2. Boot Camp Topics and Outcomes

\begin{tabular}{|c|c|c|}
\hline Research Topic & Schedule & Outcomes \\
\hline Colon cancer prevention & $\begin{array}{l}5 \text { Face-to-face meetings } \\
8 \text { Phone calls } 1 \text { Year }\end{array}$ & $\begin{array}{l}\text { Message and dissemination engaged more than } 300 \text { community } \\
\text { members. } \\
70 \% \text { of community members saw materials } \\
\text { Increase in colonoscopy and screening } \\
\text { Rural messaging included a farm auction flyer about colon } \\
\text { cancer and coffee mugs }\end{array}$ \\
\hline Asthma & $\begin{array}{l}4 \text { Face-to-face meetings } \\
5 \text { Phone calls } 8 \text { Months }\end{array}$ & $\begin{array}{l}\text { Message and dissemination engaged more than } 700 \text { community } \\
\text { members and students in } 45 \text { local schools } \\
\text { Increase in reported prescribing of inhaled corticosteroids }\end{array}$ \\
\hline $\begin{array}{l}\text { High blood pressure home } \\
\text { monitoring }\end{array}$ & $\begin{array}{l}3 \text { Face-to-face meetings } \\
6 \text { Phone calls } 4 \text { Months }\end{array}$ & $\begin{array}{l}\text { "Just check it" logo } \\
\text { Increase in home blood pressure monitoring } \\
\text { Average systolic blood pressure decreased by } 6 \mathrm{~mm} \mathrm{Hg}\end{array}$ \\
\hline PCMH & $\begin{array}{l}4 \text { Face-to-face meetings } \\
6 \text { Phone calls } 1 \text { Year }\end{array}$ & $\begin{array}{l}\text { "Medical Home is Relationship" } \\
\text { Poster for practices and organizations about PCMH } \\
\text { Reinvigorated PCMH work in several communities }\end{array}$ \\
\hline Health risk assessments & 2 Face-to-face meetings & Ongoing \\
\hline $\begin{array}{l}\text { Hypertension among urban Latinos } \\
\text { (English)* }\end{array}$ & In process & Ongoing \\
\hline $\begin{array}{l}\text { Hypertension among urban Latinos } \\
\text { (Spanish)* }\end{array}$ & In process & Planning \\
\hline Behavioral health & In process & Ongoing \\
\hline
\end{tabular}

*Boot Camp Translation pilot in an urban Latino community. $\mathrm{PCMH}$, patient-centered medical home.

the identified medical problem with the evidencebased recommendations and a process for getting that message out in a culturally relevant and evocative manner.

BCT includes an iterative, flexible schedule combining face-to-face meetings; short, focused teleconferences; and numerous E-mails (or notifications sent via the postal service, for some participants) (Table 2). BCT requires about 20 to 25 hours of participant time over a 4 - to 12 -month time span. A typical schedule includes a full-day retreat followed by 2 to 3 additional 2- to 4-hour, face-to-face sessions, interspersed with 4 to 830 minute phone calls.

\section{Typical Schedule}

The first meeting is most of a full day (up to 7 hours). A key event is a robust scientific presentation on the health topic. We use local and state medical experts to provide a 2 - to 4 -hour evidencebased presentation on the selected health topic. Community members become experts on the specific health topic, learning about the broad medical condition, the basics of the disease process, and the components of the guideline or recommendation. This presentation is not geared to a lay audience; rather, it is often the same presentation given to a group of health care professionals. This characteristic is essential because members of the HPRN CAC, who live in the project region, may become the local voice and face of the project and need to be equipped with more information than the average community member. The presentation goes slowly because each element of the scientific presentation is defined and explained in detail. Our experience is that patients and community members are eager to learn and are engaged fully in learning more than the average community member might know about a medical topic. This education benefits all project team members, providing a common understanding and language as their background.

Following the technical presentation, a conversation is facilitated about each component of the condition and evidence-based recommendation to elicit initial reactions from the group. This first brainstorming session has no wrong answers or ideas. Community members share their understanding, concerns, and initial ideas about the health condition and the guideline or recommendation. The brainstorming session transitions into an initial discussion on the key ideas or concepts about the issue (what is the message?) and a wide variety of ways to engage the community on the 
topic (how to get the message out). Depending on the project, the group may also discuss the intervention target population. The goal of the brainstorming session is not to make final decisions about messages, dissemination strategies, or target populations. This stage is used to capture all ideas and often demands a focused facilitator and some patience from the group. Copious notes are taken on poster paper and hung up around the room for review and additional comments. The medical expert who provided the presentation stays and participates because there usually are many questions about the science and medical components of the topic. The brainstorming session also serves to accelerate group bonding as individuals share their stories and the group begins to see the numerous assets available within the group.

The day ends with a recap of the technical presentation, the evidence-based recommendation, a few comments from the brainstorming session, and a brief overview of the next few sessions. During this recap, the facilitator reflects back to the group some of the key themes, if any, that emerged during the afternoon. Thus the wording for the message first begins taking shape in this recap.

Notes are compiled and distributed to participants for their review and additional comments. We have found that participants often return home and have extended kitchen-table conversations about the day and come up with many additional comments and ideas. These ideas are solicited via E-mail or phone or during in-person conversations between staff and participants. All raw notes from the poster paper are compiled by a member of the research team. Then an initial attempt is made to arrange and classify ideas. Both sets of notes are presented back to the participants for review.

Next, a series of regular phone calls are held. An agenda is sent to the group in advance. Each call has one specific task, determined by the research team with input from the group and based on the specific stage of project development. The first few tasks typically focus on developing the main messages and solidifying the target community. We strictly limit calls to 30 minutes. Respect for participant time requires adherence to time commitments and understanding that the community members and patients have busy lives. If an issue is not resolved in 30 minutes, it is held over to the next call. Typically, we have held 4 to 6 calls over an 8 -week period. We alternate the times of the calls so that all members have an opportunity to participate. This is a lively, iterative process as participants address the areas of their interest and concern related to the health condition and evidence-based recommendation.

The second face-to-face meeting is a half-day retreat. Based on the work of the first meeting and the intervening phone calls, the meeting covers a narrower focus. The group begins to refine the conceptual framework and language of the main messages around the health condition and evidence-based recommendation. Ideas generated through the previous 1 to 2 months are presented and discussed. At this point, the group has extended conversations about how to move the intervention messages effectively into the community-strategies that vary greatly depending on the target community. Conversation about each individual's perception of the words, their intellectual and visceral responses, and the variation within and among the participants makes for a lively session. The evidence-based recommendation becomes language that is accessible to the group. The target audience for the message is discussed further and defined.

A second round of 3 to 4 phone calls is held to refine the constructs and language. Each step provides further specificity to the final messaging and dissemination plan. If specific materials have been created to disseminate translated health information, images of mock-ups of these items are sent and discussed during the call.

A third face-to-face meeting is often the concluding half-day retreat. On the basis of the work of the first 2 meetings and intervening phone calls, this meeting finalizes the language and constructs so that they are understandable and accessible to patients and community members. Mock-ups of project materials are presented and discussed at this meeting for final review. Next steps are addressed because community members and patients often will be activated to keep momentum moving forward. On several occasions we have had an additional round of phone calls and a fourth face-to-face meeting to finalize the messaging and dissemination plans. For projects with current funding, additional meetings may be scheduled to plan dissemination activities, collect and interpret data, develop presentations and manuscripts, and consider the long-term sustainability of specific projects. 


\section{Results}

The High Plains Research Network has completed BCT with our CAC on 4 topics, identifying "what is the message" and "how to disseminate the message" for prevention of colon cancer, asthma, home monitoring of high blood pressure, and the patientcentered medial home (PCMH). Several other boot camps are underway for hypertension, health risk assessments, and behavioral health in primary care.

\section{Specific Examples of Boot Camp Translation in the HPRN}

The HPRN received a grant from the Centers for Disease Control and Prevention to conduct a community-based intervention to improve colorectal cancer screening in rural and frontier eastern Colorado. The HPRN uses a community-based participatory approach in all research and has an active CAC comprising local farmers, ranchers, school teachers, hardware store owners, and a few others. The first step of was for the community members to gain expertise in colorectal cancer screening. Colon Cancer Boot Camp consisted of a full-day retreat followed by 4 half-day retreats and 8 halfhour phone calls. The first day included a fulllength continuing education presentation identical to one being given to primary care providers in the state. We spent a half day on this presentation, allowing community members to interact, ask questions, and make comments. Community members had the opportunity to do a colonoscopy in our simulation laboratory. Ultimately, the community members became colorectal cancer screening experts. Based on their expertise from living in rural eastern Colorado, they changed the project's original language and approach to make the intervention more accessible to their rural communities. First, they changed the word colorectal to colon cancer to make the topic easier to talk about in public. Second, given the complexity of the concept of "screening" (primary, secondary, etc), they eliminated this language and instead used the term testing. The CAC learned and was struck by the fact that the removal of polyps can actually prevent colon cancer. As a result, the community changed the title and focus of the project to "Testing to Prevent Colon Cancer." The final set of main messages was short and simple: Colon cancer is the second leading cause of cancer death in the United States. Colon cancer is preventable. Testing is worth it. Talk to your doctor today. To move these messages and more detailed information about colon cancer throughout the target community, the group developed a multicomponent, multistrategy dissemination plan that used a combination of newspaper stories about local community members, a standard agricultural communication tool in the form of a farm auction flyer, a series of small pocket-sized cards with local personalities and messages, community talks, and a travel mug with messaging about colon cancer. A random digit dial survey revealed that the dissemination reached $65 \%$ of the target population ${ }^{23}$ and resulted in an increase in testing to prevent colon cancer. A full description of the results of this trial is beyond the scope of this manuscript and will be presented elsewhere. This program has received additional funding for replication in another rural region of Colorado.

A similar process and results occurred for the asthma boot camp, during which the community targeted and created language to increase awareness of asthma. This intervention, called Community AIR, linked community members to a practicebased asthma diagnosis and management program called Asthma Toolkits. What to say in the message was crucial because the CAC wanted to target several groups in rural Colorado and educate people who do not have a diagnosis of asthma about the common symptoms so that they would access their local health care provider (Asthma: do you have it?). They also wanted to dispel the myth that people with asthma have to limit their activities through appropriate treatment and self-management (You can control it). The CAC pushed use of "controller" medications over "inhaled corticosteroids" and helped develop a patient "toolkit" that local clinics hand out to their patients (Get your FREE Asthma Toolkit today). A common local remedy was to use an inexpensive dust mask to prevent asthma. The CAC identified this, and our team reviewed the literature about the common dust mask, finding them ineffective for controlling asthma. The CAC included in their messaging to rural famers that common dust masks are not adequate to control asthma. Dissemination of the message engaged more than 40 high schools to distribute edgy asthma educational posters, t-shirts, dust masks with the message that they are not adequate asthma care, and newspaper articles. 
In our home blood pressure program, the CAC changed our language by eliminating the term $h y$ pertension in favor of the more accessible high blood pressure. They linked the primary care practice to the patients through a message promoting home blood pressure monitoring. They included messaging about many behavioral lifestyle changes (nutrition, diet, exercise, stress management, and sodium intake) with a balance of information and action steps. BCT for the PCMH was a long process, lasting a year. Initially put off by the language of the PCMH, the CAC was excited to try and translate the medical jargon into patient-centered language. They learned the National Committee for Quality Assurance components of a PCMH and the current local, state, and national work on implementing PCMHs. The CAC used an appreciative inquiry approach to identify successful PCMH events from community members. The final product was a poster of quotes about successful medical home events that provide tangible activities that might be expected in a medical home. These messages will provide the topics for newspaper articles about the medical home as it is implemented in each rural community.

As part of an Agency for Health Research and Quality task order, the CAC has begun an abbreviated $\mathrm{BCT}$ on health risk assessments. The first day-long meeting was dedicated to learning the science and evidence for health risk assessments and reviewing the language of common assessment tools and processes for patient completion of health risk assessments. Ongoing work on this topic is to provide local, culturally appropriate methods for how and when to conduct health risk assessments in rural Colorado. Figure 1 provides information about each boot camp topic, schedule, and outcomes.

\section{Discussion}

BCT has translated evidence-based medical care, guidelines, and recommendations into reliable clinical opportunities for communities in rural Colorado to increase colon cancer testing, improve asthma diagnosis and management, improve high blood pressure care, and improve implementation of the PCMH. Through the use of this process, communities can successfully determine the content of messaging and how to best disseminate that message to maintain the scientific integrity of the evidence and assure it is locally relevant and culturally appropriate. We include several health care providers in each boot camp to assure alignment with local medical standards. By including local primary care in the process, community members are assured of a common language in both the public health and primary care setting. We have found boot camp to be an effective method for building stronger partnerships between primary care and public health as both organizations work together on a common topic. Projects have been incorporated into local primary care practices through continuing education, building practicelevel capacity, and encouraging patients to access local services for their medical care. For example, in Asthma Toolkits and Community AIR, local practices received a new spirometer, on-site training in asthma management, and toolkits to give to patients. The primary care practices derive tangible benefits as well as education and practice support through participation in HPRN projects.

A rural community becoming engaged and activated around a pertinent health issue results in a large number of individuals, organizations, health care providers, and community leaders becoming collaborators. By linking primary care, public health, community-based organizations, and schools, BCT is an effective means of developing a community of solution to address local health concerns. ${ }^{14}$ Our colon cancer prevention program began with a CAC of 10 and grew to 15 members. By the end of our program more than 230 individuals had participated. Thirty-one community members partnered with 29 clinicians to provide 50 talks to more than 900 community members. Pocket-sized cards with local photographs were placed in 162 locations: more than 1450 were taken and another 900 were distributed at talks. Sixty-four unique ads and 45 unique personal stories were printed in 15 local newspapers. This colon cancer community of solution developed and deployed a locally relevant answer to an important health concern. Likewise, Community AIR engaged more than 700 rural community members and providers in building a community of solution to address the high rate of asthma and associated morbidity. BCT provides a tangible and replicable process for building a community of solution: participants identify quickly with the tasks and outcomes necessary to improve local health.

BCT is not a rhetorical process that simply takes guidelines and recommendations and changes a few 
medical terms. It alters the conceptual framework that patients and community members hold for certain medical conditions. We do not know what we are going to end up with when we start the process. By combining both local and medical expertise, BCT creates local experts who, once educated about a specific health topic, have the capacity and local knowledge to frame the condition in the community milieu. For instance, in our first BCT related to colon cancer, rural male farmers were clearly not compelled by the concept of early detection and diagnosis of colon cancer. However, when the CAC gained a more sophisticated and nuanced understanding of colon polyps leading to colon cancer and realized that removal of polyps early can actually prevent colon cancer, they gravitated to this message for dissemination into the community. "Testing to Prevent Colon Cancer" was much more compelling to the rural and frontier communities and provided the context for a more accessible conversation between patients and providers. The Asthma Toolkit was a tangible gift from the clinic to the patient that used the common toolkit metaphor. This changed the concept of asthma as an activity-limiting disease to a condition that needed upkeep and maintenance, similar to machines and equipment common in rural Colorado.

Common to every boot camp is the message to patients and community members to access their local health care providers. The CAC is clear that while they have learned much about each medical condition, they want community members to go talk to their doctor to get the best care for their individual condition. The CAC provides talking points and relevant language so that community members can have a more thorough and meaningful conversation with their providers. Participation of providers assures that messages align with local medical standards.

BCT requires flexibility and modification. Time frames are approximate. Sometimes an issue may take several phone calls to complete, whereas for other issues groups may develop language quickly. Much of this depends on the complexity of the health condition, the evidence-based recommendation, and the cultural context of the specific community. In 4 experiences with BCT, our CACs have worked through a host of topics and ideas. Each time the final product was both intuitive and a surprise, and each time the community owned the language and proudly presented it to their community. The engagement of the local community in the process assures local and cultural relevance and increases the chance of uptake and implementation.

Not everyone likes the name boot camp for this activity; the term implies a short, intense learning activity, not military or hierarchical hazing. We have found the process to be difficult, requiring commitment to completing tasks and activities. We all come through the process stronger and with a much better message. The name itself is not important, and those who wish to should call it something else. The process of local community engagement and discovery is the crucial element. It is important to understand that the community members act as the brainstorm interpreters and idea generators, but they do not act as facilitators or note takers or serve in a longitudinal support role. The partnership of the researcher is essential. The community alone may not have the resources or expertise to proceed effectively and produce a scientifically valid message. An academic partner may be necessary to lead and facilitate the conversation and keep the process moving forward.

BCT addresses the core concepts of patientcentered care by addressing one of the barriers to advancing the quality of care in the United States. Specifically, the process provides an approach that maintains the scientific integrity of the robust evidence base in health care while honoring the local and cultural aspects of community and health. BCT addresses community health priorities, brings together key stakeholders, and develops and refines evidence-based care in a manner that respects local and individual patient preference. BCT may be an effective method for building communities of solution that address the priorities set out by the $\mathrm{Pa}$ tient-Centered Outcomes Research Institute.

\section{References}

1. Zerhouni EA. Translational and clinical sciencetime for a new vision. N Engl J Med. 2005 Oct 13. 383(15):1621-1623, 2005.

2. Westfall JM, Mold J, Fagnan L. Practice-based research-"Blue Highways" on the NIH roadmap. JAMA. 297 2007(4):403-406, 2007 Jan 2024.

3. Woolf SH, Johnson RE. The break-even point: when medical advances are less important than improving the fidelity with which they are delivered. [see comment]. Annals of Family Medicine. 3(6): 545-552, 2005 Nov-Dec 2005. 
4. McGlynn EA, Asch SM, Adams J, et al. The Quality of Health Care Delivered to Adults in the United States. N Engl J Med. 2003/6/26 348(26):26352645, 2003.

5. Genel M, Dobs A. Translating clinical research into practice: practice-based research networks-a promising solution. [Review] [41 refs]. Journal of Investigative Medicine. 51 1951(2):64-71, 2003 Mar.

6. Sung NS, Crowley WFJ, Genel M, et al. Central challenges facing the national clinical research enterprise.[see comment]. JAMA. 289 289(10):12781287, 2003 Mar 1212.

7. Graham RP, James PA, Cowan TM. Are clinical practice guidelines valid for primary care? J Clin Epidemiol 2000;53:949-54.

8. Betancourt JR, Green AR, Carrillo JE, AnanehFirempong O 2nd. Defining cultural competence: a practical framework for addressing racial/ethnic disparities in health and health care. Public Health Rep 2003;118:293-302.

9. Minkler M. Community-based research partnerships: challenges and opportunities. J Urban Health 2005;82(2 Suppl 2):ii3-12.

10. Israel BA, Parker EA, Rowe Z, et al. Communitybased participatory research: lessons learned from the Centers for Children's Environmental Health and Disease Prevention Research. Environ Health Perspect 2005;113:1463-71.

11. Metzler MM, Higgins DL, Beeker CG, et al. Addressing urban health in Detroit, New York City, and Seattle through community-based participatory research partnerships. Am J Public Health 2003;93: 803-11.

12. Israel BA, Lichtenstein R, Lantz P, et al. The Detroit Community-Academic Urban Research Center: development, implementation, and evaluation. J Public Health Manag Pract 2001;7:1-19.

13. Wallerstein NB, Duran B. Using community-based participatory research to address health disparities. Health Promot Pract 2006;7:312-23.

14. Folsom Group. Communities of solution: the Folsom Report revisited. Ann Fam Med 2012;10: 250-60.

15. Westfall JM, Van Vorst RF, McGloin J, Selker HP. Triage and diagnosis of chest pain in rural hospitals: implementation of the ACI-TIPI in the High Plains Research Network. Ann Fam Med 2006;4:153-8.

16. Westfall JM, VanVorst RF, Main DS, Herbert C. Community-based participatory research in practice-based research networks. Ann Fam Med 2006; 4:8-14.

17. Van Vorst RF, Crane LA, Barton PL, Kutner JS, Kallail KJ, Westfall JM. Barriers to quality care for dying patients in rural communities. J Rural Health 2006;22:248-53.

18. Westfall JM, Zittleman L, Staton EW, et al. Card studies for observational research in practice. Ann Fam Med 2011;9:63-8.

19. Van Vorst RF, Araya-Guerra R, Felzien M, Fernald D, Elder N, Duclos C, Westfall JM. Rural community members' perceptions of harm from medical mistakes: a High Plains Research Network (HPRN) Study. J Am Board Fam Med 2007;20:135-43.

20. Overholser L, Zittleman L, Kempe A, et al. Use of colon cancer testing in rural Colorado primary care practices. J Gen Intern Med 2009;24:1095-100.

21. Rim SH, Zittleman L, Westfall JM, Overholser L, Froshaug D, Coughlin SS. Knowledge, attitudes, beliefs, and personal practices regarding colorectal cancer screening among health care professionals in rural Colorado: a pilot survey. J Rural Health 2009; 25:303-8.

22. Coughlin SS, Costanza ME, Fernandez ME, et al. CDC-funded intervention research aimed at promoting colorectal cancer screening in communities. Cancer 2006;107(5 Suppl):1196-204.

23. Zittleman L, Emsermann C, Dickinson M, Norman N, Winkelman K, Linn G, Westfall JM. Increasing colon cancer testing in rural Colorado: evaluation of the exposure to a community-based awareness campaign. BMC Public Health 2009;9:288.

24. Bender BG, Dickinson P, Rankin A, Wamboldt FS, Zittleman L, Westfall JM. The Colorado Asthma Toolkit Program: a practice coaching intervention from the High Plains Research Network. J Am Board Fam Med 2011;24:240-8.

25. Young WF, McGloin J, Zittleman L, West DR, Westfall JM. Predictors of colorectal screening in rural Colorado: testing to prevent colon cancer in the high plains research network. J Rural Health 2007;23:238-45. 